\section{Advocacy in a}

\section{Global Pandemic}

Cassie Chenoweth

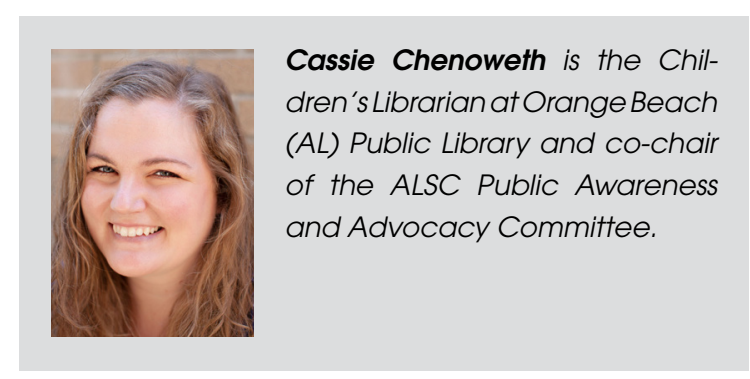

7 he COVID-19 pandemic has shaken up our professional and personal lives more than anyone could have expected. There has never been a more important time to advocate for libraries, specifically children's services. We have all learned some incredibly valuable lessons about library advocacy during this unprecedented time. The following are library advocacy tips to be used at any time, pandemic or not.

- Show Your Worth. As library professionals, we know libraries are more than just buildings filled with books, but do your stakeholders know that? Do they know you provide programming that is being translated online? Do they know you offer online reference services? Now is the time to show your community what libraries provide. Many libraries have focused their attention to their online resources, from e-books to skill-building services.

- Get Back to Basics. As libraries closed in March 2020, many children's librarians began to offer virtual storytimes. Whether it was recorded and uploaded on YouTube, live on Facebook, or in a Zoom room, children's librarians got creative to reach their littlest patrons. A surprising silver lining of online storytimes was the lack of constant interruptions from toddlers, preschoolers, and, let's be honest, their caregivers. One of the key components of storytime, sharing early literacy tips, was a lot easier to implement. We found that we were able to explain exactly why we do what we do without the little ones deciding it was the perfect time to take a lap around the storytime room. For example, after singing "Itsy Bitsy Spider," we talked about how singing helps us slow down our words, which will help kids when they learn to read. By sharing tips and getting to the roots of our librarianship skills, we are reminding others and ourselves why libraries are so important.

- More than Face-to-Face Interaction. Yes, customer service is the cornerstone of library work, especially in public libraries. But what happens when the usual form of customer service, face-to-face interaction, isn't possible? We get creative. Some libraries offered curbside services to patrons. Many libraries created personalized recommendation services and "grab bag" options for patrons. When programming went virtual, librarians interacted with patrons through Zoom or live Facebook streams. It's not ideal, but even a little bit of personalization can go a long way in library advocacy.

- Professional Development. Many libraries were able to offer work-fromhome opportunities when their doors were closed. Online webinars and other professional development opportunities were the simplest ways to "work" when we couldn't be in the library. ALSC offers many archived webinars that became a helpful tool when looking for ways to grow professionally during some unprecedented downtime.

- Virtual Meetings Aren't All Bad. When word came down that ALSC was shifting process and professional award committees to a hybrid model, where work and meetings occur virtually throughout the service year with conference attendance being optional, there was some understand- 
able push back from fans of in-person committees. There was talk of lack of networking and collaboration opportunities. Then COVID-19 hit. Everyone was forced to go virtual. And you know what? It wasn't all bad! More people were able to save time and money by attending the ALA Virtual. Everyone got a little more used to seeing themselves on camera for a Zoom call. Technical kinks were straightened out, and we all realized meeting virtually was a lot easier in some cases. Of course, the excitement of in-person conference can never be replicated, but we learned that important work can be done in many ways.

Library advocacy is all about creativity and flexibility. During the pandemic, library professionals were tested and proved that libraries and, specifically, children's services, are vital parts of our communities. \& 